\title{
CONCEPÇÕES DE FORMAÇÃO PROFISSIONAL TÉCNICA DE NÍVEL MÉDIO ADOTADAS PELO IFRN: ESPECIFICIDADES E (DES)CONTINUIDADES
}

\author{
J. M. N. SILVA ${ }^{1 *}$ e A. CABRAL NETO ${ }^{2}$ \\ ${ }^{1}$ Instituto Federal de Educação, Ciência e Tecnologia do Rio Grande do Norte - IFRN \\ ${ }^{2}$ Universidade Federal do Rio Grande do Norte \\ moises.silva@ifrn.edu.br
}

Artigo submetido em agosto/2015 e aceito em setembro/2015

DOI: 10.15628/holos.2015.3315

\section{RESUMO}

$\mathrm{O}$ artigo trata das concepções de formação profissional técnica de nível médio adotadas pelo IFRN. Discute essas concepções a partir dos quatro Projetos PolíticoPedagógicos (PPPs) construídos no período de 1970 a 2010, abrangendo três institucionalidades: ETFRN (1970-1998), CEFET-RN (1999-2008) e IFRN (a partir de 2009). O objetivo é analisar como se configuram as concepções de formação profissional adotadas nos PPPs, com ênfase nas especificidades e (des)continuidades entre os referidos projetos. Como orientação teórico-metodológica adotou-se a dialética e como procedimento de pesquisa a revisão bibliográfica, a pesquisa documental e as entrevistas com sujeitos que participaram do grupo de trabalho que coordenou a elaboração dos PPPs. Os resultados evidenciam que entre os PPPs, dos períodos analisados, há mais continuidades do que rupturas em relação às concepções de formação profissional adotadas. Conclui-se que, embora a utopia do IFRN, no momento atual, seja consolidar, em suas ações educativas, a concepção de formação humana integral, na prática, essa é apenas uma possibilidade em construção.

PALAVRAS-CHAVE: Educação profissional, Formação profissional técnica de nível médio, Formação unilateral, Formação omnilateral.

\section{CONCEPTIONS OF TECHNICAL TRAINING OF MIDDLE LEVEL ADOPTED BY IFRN: SPECIFICITIES AND (DIS)CONTINUITIES}

\begin{abstract}
The article deals with the conceptions of technical training of middle level adopted by IFRN. Discusses these concepts from the four Political-Pedagogical Projects (PPPs) built in the 1970-2010 period, spanning three institutionalities: ETFRN (1970-1998), CEFET-RN (1999-2008) and IFRN (from 2009). The goal is to analyze the configuration of the conceptions of training adopted in PPPs, emphasizing the specifics and (dis) continuities between those projects. As theoretical and methodological orientation adopted the dialectic and as
\end{abstract}

a research procedure literature review, document research and interviews with subjects who participated in the working group that coordinated the preparation of PPPs. The results show that among the PPPs, the analyzed periods, there is more continuity than rupture in relation to vocational training concepts adopted. It is concluded that while the utopia of IFRN, at present, is consolidating in its educational activities, the concept of integral human formation, in practice, this is only a possibility under construction.

KEYWORDS: Professional education, Technical training of middle level, Unilateral formation, Omnilateral formation. 


\section{NOTAS INTRODUTÓRIAS}

O Instituto Federal de Educação, Ciência e Tecnologia do Rio Grande do Norte (IFRN), ao longo de mais de um século de existência, mudou de institucionalidade sete vezes, as quais acarretaram, progressivamente, alterações infraestruturais, organizacionais, administrativas e pedagógicas, esta última envolvendo ampliação e diversificação das ofertas educacionais, redimensionamento da função social, concepção de formação profissional, currículo, processo ensino-aprendizagem e fomento da formação e valorização dos professores. Motivados por essa evolução institucional desenvolvemos tese de doutorado, apresentada no curso de PósGraduação em Educação, da Universidade Federal do Rio Grande do Norte, com foco nos Projetos Políticos-Pedagógicos (PPPs) desenvolvidos pela Instituição. Este artigo se constitui em um recorte da referida tese e tem por objetivo analisar a configuração das concepções de formação profissional técnica de nível médio adotadas nos PPPs da Instituição, no período de 1970 a 2010, com ênfase nas especificidades e (des)continuidades desses Projetos.

Como orientação teórico-metodológica deste estudo adotamos a dialética, para explicar as mediações necessárias entre cada projeto pedagógico e as condições em que eles foram concebidos, pois, como assevera Kosik (1976), o todo não é imediatamente cognoscível para o homem. E como procedimento técnico utilizamos a revisão bibliográfica, a pesquisa documental e as entrevistas realizadas com oito sujeitos, codificados com os nomes fictícios de João, Paulo, Marcos, Sara, Rebeca, Rute, Débora e Raquel, que participaram do grupo de trabalho coordenador da elaboração dos PPPs.

A relevância deste artigo consiste no desvelamento da forma pela qual o IFRN, em três fases distintas de sua institucionalidade, responde às políticas educacionais do país, particularmente no que se refere às concepções de formação profissional consubstanciadas nos PPPs, além de produzir conhecimentos que contribuem para o aperfeiçoamento dos processos educacionais da Instituição. Ademais, o artigo está organizado, em três seções seguidas de considerações finais. Na primeira parte discutimos as concepções de formação profissional na ETFRN (1970-1998); na segunda, as concepções de formação profissional no CEFET-RN (19992008); e na terceira, as concepções de formação profissional no IFRN (a partir de 2009). Nas considerações finais realçamos aspectos relevantes das especificidades e (des)continuidades dos PPPs e das concepções de formação profissional prescritas nesses documentos institucionais.

\section{CONCEPÇÕES DE FORMAÇÃO PROFISSIONAL NA ETFRN (1970-1998)}

Nas três décadas em que o IFRN permaneceu sob a denominação de Escola Técnica Federal do Rio Grande do Norte (ETFRN), a Instituição ofertou sete cursos técnicos de nível médio: Estradas, Mineração, Edificações, Eletrotécnica, Mecânica, Geologia e Saneamento, objetivando atender as demandas do mercado de trabalho decorrentes do modelo desenvolvimentista que se impôs ao país pelo Regime Civil-Militar, o qual requeria , prioritariamente, a formação de técnicos para o setor secundário da economia, de modo a atender aos propósitos do capital e aos programas de desenvolvimento infraestrutural do Estado brasileiro.

As matrizes curriculares dos referidos cursos foram estruturadas, segundo os princípios exarados na Lei n. 5.692/1971 e no Parecer n. 45/1972 do Conselho Federal de Educação (CFE), 
em duas partes: educação geral (núcleo comum nacional e parte diversificada ajustada à realidade local e regional), com carga horária de 1.440 horas, e formação especial (parte profissionalizante), com 1.290 horas, complementada pelo estágio orientado da profissão, com 720 horas, e tinham como premissa dominante uma educação mais especializada e técnica, o aprender a fazer, em detrimento de uma formação mais ampla dos estudantes. (BRASIL, 1971; 1972).

Até 1994, a lógica de distribuição das disciplinas nas matrizes curriculares era a mesma: educação geral ministrada exclusivamente no início do curso e formação especial, com maior ênfase no final, como se fossem dois cursos distintos (ensino médio e técnico) em um, inclusive com objetivos diferentes. Ou seja, a composição das matrizes curriculares apontava mais para uma justaposição dos ensinos propedêutico e técnico do que para uma articulação entre eles, uma vez que as disciplinas de educação geral, ministradas em primeiro lugar, destinavam-se a propiciar ao educando os conhecimentos humanísticos para a continuidade de estudos, enquanto as de formação especial, veiculadas após aquelas, representavam o fim último dos cursos: a formação e a qualificação para ingresso no mercado de trabalho.

Esse forma de conceber a organização dos cursos segue a lógica indicada por Cury et al. (1982, p. 20) na medida em que: “[...] o ensino técnico-profissional manteve-se sem mudanças positivas em relação ao que era antes da Lei [n. 5.692/1971]: um ensino com marcada predominância do caráter profissionalizante, apenas temperado por certa dose de educação geral."

É imperioso ressaltar que até 1994 a ETFRN não possuía Projeto Político-Pedagógico. As ações acadêmicas da Instituição eram consolidadas em Organizações Didáticas - entre 1985 e 1994, os cursos técnicos na ETFRN eram regulamentados pela Organização Didática aprovada por meio da Portaria n. 5, de 14 de fevereiro de 1985, do Ministério da Educação (MEC). (ETFRN, 1985) -, elaboradas a partir de diretrizes fixadas na legislação educacional vigente, além de pareceres emanados do CFE e de orientações normativas do próprio MEC. Como bem observou o professor entrevistado João, até 1994 “[...] não havia uma Organização Didática fundamentada, mas tão-somente propostas de estruturação e organização de itinerários formativos rígidos em diferentes ocupações de nível técnico."

De acordo com a Organização Didática de 1985, a ETFRN tinha por finalidade ministrar o ensino de $2 \circ$ grau, em consonância com os fins da educação nacional expressos na Lei de Diretrizes e Bases (LDB) de 1961 e por objetivos: a) desenvolver as potencialidades do educando com vistas a sua autorrealização, preparação para o trabalho e para o exercício consciente da cidadania; b) proporcionar, mediante a realização de programas de educação continuada, estudos de aperfeiçoamento ou atualização; c) promover a realização de cursos especiais de formação de mão de obra, em atendimento às necessidades do mercado de trabalho local e regional; e d) promover o intercâmbio com outras instituições educacionais da comunidade e com empresas, possibilitando o pleno desenvolvimento de sua capacidade e fomentando a absorção dos técnicos pelo mercado de trabalho. Além disso, a ETFRN estabeleceu que "[...] os cursos técnicos regulares visariam proporcionar a formação de técnicos de nível médio para o setor secundário da economia." (ETFRN, 1985, p. 3).

Como se pode depreender, os objetivos da ETFRN expressavam uma vinculação da Instituição aos setores produtivos da economia, de modo que sua função precípua era a 
formação e qualificação de profissionais para atender às necessidades do mercado de trabalho local e regional, o qual possuía base técnica eletromecânica e se assentava no modelo de produção taylorista-fordista, que exigia mão de obra especializada para a realização de tarefas específicas no processo produtivo. Literalmente correspondia ao que Frigotto (2003, p. 26) ressalta quando afirma: "[...] trata-se de subordinar a função social da educação de forma controlada para responder às demandas do capital".

Assim sendo, podemos conjecturar que a ETFRN, no período de 1970 a 1994, assumiu como concepção de formação profissional técnica de nível médio, a formação unilateral, uma vez que expressava centralidade na dimensão laboral, ou seja, uma formação de caráter instrumental, especializada, para a ocupação de um posto específico e bem definido no mercado de trabalho: o de assistir engenheiros e administradores e executar atividades em que a tecnologia requeresse profissionais com tal formação. Essa presunção encontra respaldo em Machado (1982), quando destaca que, no contexto da profissionalização promovida pela Lei n. $5.692 / 1971$, as Escolas Técnicas deveriam oferecer aqueles cursos que estivessem em consonância com o mercado de trabalho local ou regional, e que teriam a tarefa de moldar, seja pela disciplina, seja pelo conteúdo do ensino, aquele profissional que melhor se ajustasse às necessidades empresariais.

Em 1995, a ETFRN implantou seu primeiro Projeto Político-Pedagógico, intitulado Proposta Curricular, o qual, construído coletivamente entre 1993 e 1994, visava aprimorar a qualidade da educação oferecida pela Instituição, no sentido de, por um lado, responder às novas demandas dos setores secundário e terciário da economia e da própria sociedade e, por outro, superar a dicotomia homem-cidadão e técnico-profissional, vinculando cidadania e tecnologia. Para tanto, a Instituição assumiu como função social: produzir conhecimentos científicos e tecnológicos que possibilitassem ao estudante um padrão de competência técnico-profissional para desenvolver tecnologias no processo produtivo e na prestação de serviços à população, atuar na pesquisa, e ampliar sua leitura de mundo, para interferir na sociedade e transformá-la. E como concepção de formação profissional a "[...] formação omnilateral do homem, entendida como desenvolvimento da totalidade das capacidades humanas, sem perder de vista seus determinantes históricos e a possibilidade de uma ação mais efetiva no meio social." (ETFRN, 1995, 57).

Segundo a pedagoga Rute, essa concepção de formação estava muito clara nos princípios dessa Proposta Curricular: "uma formação em uma perspectiva omnilateral do técnico-cidadão, para o domínio dos recursos científicos e tecnológicos, que the possibilite atuar no sistema produtivo e participar criticamente do processo de transformação social em função dos interesses coletivos."

A concepção de formação adotada representa, conceitualmente, uma ruptura com a formação unilateral, instrumental, cingida à ocupação de postos específicos no mercado de trabalho, que prevalecia na Instituição, desde a década de 1970, em consonância como o modelo de desenvolvimento e a política educacional do Regime Civil-Militar. Isto porque, a omnilateralidade concebe a formação integral do ser humano - social, moral, ética, intelectual, artística, afetiva, emocional, laboral etc. -, para que possa compreender as relações que se estabelecem nas atividades socioculturais e no mundo do trabalho. 
Para a consecução dessa Proposta Curricular, a ETFRN abandonou a oferta de cursos técnicos e concebeu um modelo pedagógico baseado em seis áreas de conhecimento: Construção Civil, Eletromecânica, Geologia e Mineração, Informática, Serviços e Tecnologia Ambiental, cada uma com uma série de habilitações profissionais, o que alargou a formação, pois possibilitava ao educando ter várias habilitações dentro da área escolhida e, não apenas uma, como ocorria anteriormente.

A estrutura das matrizes curriculares, nesse modelo, comportava disciplinas de base científica (2.280 horas), comum a todas as áreas; base tecnológica (1.680 horas), comum a todas as habilitações dentro de uma área; base específica, de acordo com cada uma das habilitações profissionais (480 horas); e estágio orientado da profissão (360 horas). Ademais, previa, para as três primeiras séries, o desenvolvimento da base científica concomitante à base tecnológica, de modo a estabelecer, em tese, por um lado, a articulação entre esses conhecimentos desde a primeira série de cada uma das áreas e, assim, afastar o sentido da justaposição dos conhecimentos como vinha acontecendo nas matrizes anteriores e, por outro, apontar para a possibilidade da concepção de formação omnilateral adotada; e para a quarta e última série, basicamente, as disciplinas de base específica, de acordo com cada habilitação profissional escolhida pelo educando e derivada da respectiva área. (ETFRN, 1995).

De acordo com o professor João, para viabilizar esse modelo pedagógico, a ETFRN instaurou um Plano de Ação, no qual foram estabelecidos "[...] horários comuns para a realização de reuniões pedagógicas em cada uma das áreas de conhecimentos, nas quais eram debatidas questões gerais e específicas para a sua operacionalização, bem como, era feito um acompanhamento e utilizados mecanismos de avaliação."

Assim, constatamos que a Proposta Curricular de 1995 representou um expressivo avanço às ações educativas na ETFRN, tanto no aspecto da organização curricular (ao substituir os cursos por áreas de conhecimento), quanto no desenho das matrizes curriculares (as disciplinas de caráter tecnológico estavam presentes juntamente com as científicas desde a primeira série de cada uma das áreas de conhecimento) e na metodologia (previa o trabalho docente interdisciplinar, no sentido do diálogo entre os conhecimentos científicos, entre os tecnológicos e entre ambos). Além disso, a ETFRN assumiu a formação omnilateral como concepção de formação, ou seja, assumiu formar o profissional-cidadão, um sujeito com qualificação técnica para inserir-se no mundo do trabalho e, também, para exercer sua cidadania, de modo consciente, ético e crítico.

Apesar de todo o esforço dispendido coletivamente para a construção dessa Proposta Curricular, a ETFRN não teve tempo suficiente para reformulá-la/ajustá-la ou consolidá-la, sendo obrigada a interromper abruptamente a sua implementação em 1998, em consequência da reforma da educação profissional promovida pelo governo Cardoso, por meio do Decreto $\mathrm{n}$. 2.208/1997.

\section{AS CONCEPÇÕES DE FORMAÇÃO PROFISSIONAL NO CEFET-RN (1999-2008)}

O Decreto n. 2.208/1997 instituiu a organização da educação profissional em três níveis (básico, técnico e tecnológico), estabeleceu a independência do nível técnico do ensino médio, impôs que o currículo desse nível fosse estruturado em disciplinas agrupadas sob a forma de 
módulos, com terminalidade e firmou como finalidade dessa modalidade: formar profissionais aptos a exercer atividades específicas no mundo produtivo. (BRASIL, 1997). Ou seja, o governo Cardoso tratou, como assevera Frigotto (2001, p. 80), de vincular a educação profissional "[...] a uma perspectiva de adestramento de acomodação, [...] de conformar um cidadão mínimo, que pensa minimamente e que reaja minimamente."

Para se ajustar às determinações do mencionado Decreto, o Centro Federal de Educação Tecnológica do Rio Grande do Norte (CEFET-RN) extinguiu, em 1998, o currículo implantado em 1995; promoveu a construção de dois projetos curriculares independentes: um para o ensino médio e outro para o nível técnico; e ampliou e diversificou as ofertas educacionais, com cursos nos três níveis da educação profissional e com o curso de ensino médio propedêutico.

De acordo com o projeto curricular do nível técnico - intitulado Projeto de Reestruturação Curricular -, os cursos teriam como características, além das estabelecidas pelo Decreto $\mathrm{n}$. 2.208/97, a organização em seis áreas profissionais (Construção Civil; Indústria; Informática; Meio Ambiente; Mineração; e Turismo e Hospitalidade) e a finalidade de desenvolver no educando aptidões para a vida produtiva, de forma rápida e flexível. Tanto que, o desenho curricular de todos os cursos, consubstanciado nesse Projeto, especificava as competências profissionais do técnico, as funções e as respectivas subfunções de cada curso e a composição dos três módulos, que tinham, cada um, a duração aproximada de seis meses e caráter de terminalidade, o que permitiria ao estudante algum tipo de exercício profissional após a conclusão de cada um dos módulos, e o diploma de técnico, após concluir os três e o estágio curricular, desde que o estudante apresentasse o certificado de conclusão do ensino médio. (CEFET-RN, 1999).

Ou seja, a organização dos cursos foi concebida tão-somente para estreitar a relação entre a escola e processo de acumulação capitalista, mediante o desenvolvimento da aptidão para a vida produtiva, a qual se daria pela (re)qualificação profissional e a (re)inserção no mercado de trabalho. Não admitia, portanto, a perspectiva de uma formação mais ampla do educando, uma vez que os cursos eram independentes do ensino médio. Por isso, mas não apenas, a construção desse Projeto de Reestruturação Curricular sofreu resistência por parte dos docentes, conforme se depreende da fala da professora Sara: "[...] embora se desejasse uma ampla participação, efetivamente a participação era tímida nas discussões da concepção geral do projeto, centrando-se basicamente na reformulação das matrizes para atender a nova proposta."

O CEFET-RN assumiu nesse Projeto como função social: "A formação do profissionalcidadão nos diferentes níveis da educação profissional, através de um processo de apropriação e de produção de conhecimentos científicos e tecnológicos, visando a uma atuação competente no mundo produtivo" (CEFET-RN, 1999, p. 116); e como concepção de formação profissional "[...] o sujeito integral, o qual, no confronto com outros sujeitos, afirma a sua identidade social e política, e reconhece a identidade de seus semelhantes." (CEFET-RN, 1999, p. 48). Conjecturamos que essas perspectivas são incoerentes com o desenho da organização curricular delineada, particularmente, para os cursos de nível técnico, pois como é possível formar um sujeito integral, um profissional-cidadão se os cursos se limitavam às disciplinas técnicas e tinham como finalidade apenas a formação estreita para o mercado de trabalho?

A respeito da concepção de formação profissional adotada nesse Projeto, o professor Paulo, afirmou: "foi uma concepção instrumental, especializada, empobrecida pela ausência de 
conteúdos humanísticos, na perspectiva do adestramento, da alienação do futuro profissional, muito adequado ao sistema de exploração capitalista mais intenso." Esta fala ratifica a nossa presunção de que a concepção de formação profissional conformada por meio do desenho curricular dos cursos de nível técnico era, de fato, a formação unilateral, pois diz respeito a uma formação centrada no desenvolvimento de competências, em sintonia com e para o mundo produtivo. Ademias, essa concepção representa um retrocesso em relação a Proposta Curricular de 1995, que havia assumido a concepção de formação na perspectiva da omnilateralidade, da formação integral e a estrutura organizacional dos cursos apontavam para tal.

O Projeto de Reestruturação Curricular de 1999 também foi breve. Em 2004, o CEFET-RN, com base no Decreto n. 5.154/2004, do governo Lula, que estabeleceu uma nova organização para a educação profissional (BRASIL, 2004), construiu um novo Projeto, intitulado Projeto Político-Pedagógico do CEFET-RN: um documento em construção, o qual foi implantado em 2005. Por esse Projeto, a Instituição passou a atuar com a oferta dos cursos técnicos integrados ao ensino médio em Edificações, Eletrotécnica, Mecânica, Informática, Controle Ambiental, Geologia e Mineração e Turismo, todos estruturados com uma carga horária máxima de 4.000 horas, distribuídas em quatro séries anuais, sendo 2.190 horas de núcleo comum (disciplinas do ensino médio); 360 horas de parte diversificada; 1.050 horas, no máximo, de formação profissional específica, e 400 horas de prática profissional. Ademais, assumiu como função social: "Promover a educação científico-tecnológico-humanística visando à formação integral do profissionalcidadão crítico-reflexivo, competente técnica e eticamente e comprometido efetivamente com as transformações sociais, políticas e culturais" (CEFET-RN, 2005, p. 77). E como concepção de formação profissional, a formação humana integral do profissional-cidadão.

A respeito dessa concepção de formação, o professor Marcos acrescentou: “[...] a gente tentou retomar a concepção da Proposta Curricular de 1995, que é a questão da pluralidade das ciências, a não separação entre formação geral e formação específica, a concepção de omnilateralidade, da formação humana integral." A omnilateralidade diz respeito ao fato do ser humano ser desenvolvido em todas as suas potencialidades - intelectual, laboral, social, moral, ética, afetiva, etc. - a fim de que possa compreender as relações que se estabelecem nas atividades socioculturais e no mundo do trabalho, ampliar sua leitura de mundo e exercer de forma autônoma e ativa sua cidadania em todos os processos sociais.

Para a consecução dessa concepção de formação, a relação entre conhecimentos gerais e específicos que compõem o currículo integrado devem estar imbricados e de forma contínua ao longo do curso, pois isso favorecerá, por um lado, a superação da dicotomia entre teoria e prática e da hierarquia das disciplinas e, por outro, um entrosamento entre os professores que atuam em disciplinas do ensino médio com os de formação profissional. Até porque, como afirma Machado (2010a, p. 81), “[...] Se a realidade existente é uma totalidade integrada não pode deixar de sê-lo o sistema de conhecimentos produzidos pelo homem a partir dela, para nela atuar e transformá-la." Assim, a materialização do currículo integrado e, consequentemente, da concepção de formação adotada precisa ser favorecida por práticas pedagógicas interdisciplinares, pensadas coletivamente pelo coletivo dos docentes de cultura geral e de cultura técnica.

Todavia, ao perscrutar o arranjo das matrizes curriculares dos cursos técnicos integrados, verificamos a mesma lógica dos cursos das décadas de 1970/1980: o primeiro ano composto apenas por disciplinas do núcleo comum e da parte diversifica, e o quarto e último ano, com 
predominância das disciplinas de formação profissional, de modo que a lógica curricular delineada para os cursos pelo Projeto Político-Pedagógico de 2004, mais parece um ajuntamento de disciplinas que antes estavam separadas impositivamente pelo Decreto n. 2.208/1997 do que uma integração propriamente dita, pois não aponta para o relacionamento entre as disciplinas de conhecimentos gerais e específicos de forma contínua ao longo do curso. Na realidade, essa distribuição desigual, ao longo do curso, das disciplinas do ensino médio e da formação técnica, revela-se como um impedimento ao desenvolvimento de um currículo integrado, considerando que a presença dessas disciplinas em um mesmo currículo não implica, necessariamente, a existência de uma integração curricular.

Do exposto, podemos afirmar que, no período de 1999 a 2008, o CEFET-RN construiu dois Projetos Político-Pedagógicos com duas concepções de formação profissional distintas: o primeiro, que vigorou de 1999 a 2004, adotou a concepção na perspectiva da formação unilateral, uma vez que arquitetou os cursos de nível técnico em vinculação estreita ao mundo produtivo; e o segundo, que vigorou de 2005 a 2008, a concepção na perspectiva da formação integral, consubstanciada, em tese, por um currículo integrado, tendo o trabalho, a ciência, a tecnologia e a cultura como eixos estruturantes. Essa segunda concepção representou, ao mesmo tempo, um avanço em relação à anterior e um retorno a de 1995. Todavia, vale dizer, com base no desenho das matrizes curriculares dos cursos técnicos integrados, que essa concepção de formação se colocou como uma possibilidade, um horizonte, para o CEFET-RN.

\section{A CONCEPÇÃO DE FORMAÇÃO PROFISSIONAL NO IFRN (A PARTIR DE 2009)}

A transformação do CEFET-RN em IFRN, no final de 2008, implicou ampliação estrutural de cinco campi em 2008 para dezesseis, em 2010, distribuídos em todo o Estado do Rio Grande do Norte - e a construção de um novo Projeto Político-Pedagógico, o qual teve início em 2009 resultando, em 2012, no documento intitulado Projeto Político-Pedagógico do IFRN: uma construção coletiva, pois envolveu a comunidade acadêmica de cada um dos campi.

De acordo com esse Projeto, o IFRN deve promover uma ação formativa pública, laica, gratuita e de qualidade, pautada em uma visão humanística e ancorada nos seguintes princípios: justiça social; gestão democrática; integração, na perspectiva interdisciplinar; verticalização do ensino e sua articulação com a pesquisa e a extensão; formação humana integral; e inclusão social. Em consequência, assumiu como função social: "Ofertar educação profissional e tecnológica comprometida com a formação humana integral, com o exercício da cidadania e com a produção e a socialização do conhecimento, visando, sobretudo, à transformação da realidade na perspectiva da igualdade e da justiça sociais." E como concepção de formação profissional técnica de nível médio, a "[...] formação omnilateral, que favorece, nos mais variados âmbitos, o (re)dimensionamento qualitativo da práxis social." (IFRN, 2012, p. 18).

Enquanto a função social indica que a Instituição manteve as suas ofertas educativas com o fito de formar o profissional-cidadão, um sujeito com domínio dos conhecimentos científicos, tecnológicos e culturais, qualificado para o mundo do trabalho e para o exercício da vida pública, capaz de contribuir com o desenvolvimento do Estado e da região, na perspectiva da transformação, a concepção de formação profissional aponta para uma formação que considera o desenvolvimento de todas as potencialidades do estudante e não apenas os saberes necessários para a sua adaptação ao mundo produtivo. Literalmente, formar o homem, como 
afirma Gramsci (1995, p. 136), "[...] capaz de pensar, de estudar, de dirigir ou de controlar quem dirige."

O Projeto Político-Pedagógico do IFRN de 2009, conservou a oferta dos cursos técnicos integrados, por meio do currículo integrado, assentando na perspectiva da politecnia e da indissociabilidade do trabalho, ciência, tecnologia e cultura. Segundo a professora Rebeca, o IFRN tem como concepção fundante "[...] o currículo integrado, a integração, em uma perspectiva interdisciplinar, tanto entre a educação profissional e a educação básica quanto entre as diversas áreas profissionais; a formação humana integral, com a produção, a socialização e a difusão do conhecimento." Ou seja, a Instituição assume, com o currículo integrado, a perspectiva da superação incondicional da dualidade entre educação geral e formação técnica, favorecendo à construção de conhecimentos e valores indispensáveis à formação do educando, não apenas para sua inserção no mundo do trabalho, mas também para o exercício consciente da cidadania, emancipação e transformação da sociedade.

No entanto, os cursos técnicos integrados passaram a ser estruturados em eixos tecnológicos - "[...] uma linha imaginária tendo à sua volta tecnologias que por ela são atraídas. Isso significa certa unidade e convergência dessas tecnologias, que devem ter poder de mútua aproximação, de dar uma direção ao movimento dessa linha imaginária" (MACHADO, 2010b, p. 96) -, conforme definidos no Catálogo Nacional de Cursos Técnicos, desdobrados em núcleos politécnicos comuns - conjunto de conhecimentos científicos, de intervenções na natureza, de processos produtivos e culturais e de aplicações científicas às atividades humanas, relacionadas às dimensões socioeconômicas, ao uso e à produção de técnicas e de tecnologias (MACHADO, 2010b) -. (IFRN, 2012).

Com efeito, as matrizes curriculares dos cursos técnicos integrados foram organizadas em quatro séries, com um conjunto de disciplinas distribuídas por três núcleos politécnicos: estruturante, com 2.340 horas e composto pelas disciplinas do ensino médio; articulador, com 360 horas e constituído por disciplinas tanto do ensino médio quanto da formação técnica; e tecnológico, com, no máximo, 1.140 horas e apenas disciplinas de formação técnica específica; além de 400 horas de prática profissional e 100 horas de seminários curriculares obrigatórios, perfazendo uma carga horária total máxima de 4.100 horas. (IFRN, 2012).

Perscrutando as matrizes curriculares dos cursos, podemos inferir, a julgar pelas disciplinas que comportam, que os núcleos estruturante, articulador e tecnológico correspondem ao núcleo comum, parte diversificada e formação profissional, respectivamente, do Projeto Político-Pedagógico de 2004. Ou seja, o desenho organizacional das matrizes tem a conotação de algo novo, ímpar, mas na realidade não passa da forma tradicional estabelecida ainda no período do Regime Civil-Militar, por intermédio da Lei n. 5.692/1971, com outra nomenclatura. De novo mesmo é o fato de que as disciplinas do núcleo tecnológico estão presentes da primeira à última série em todos os cursos, sem predominar em nenhuma delas, o que prenuncia o favorecimento do currículo integrado, na perspectiva do diálogo, desde o início do curso, entre as disciplinas dos três núcleos politécnicos, reconhecendo que a interdisciplinaridade é um dos elementos centrais nesse tipo de currículo e favorecendo a formação integrada do profissional-cidadão.

De fato, o trabalho interdisciplinar é imprescindível para a consolidação de práticas pedagógicas que ensejem tanto a articulação das dimensões trabalho, ciência, tecnologia e cultura, bases do currículo integrado, quanto à aplicação de conhecimentos teórico-práticos 
inerentes a cada curso técnico e ao eixo tecnológico do qual faz parte, bem como para o êxito da materialização da formação integrada do educando e, por conseguinte, de sua formação integral. Como assevera Ramos (2005, p. 122): “[...] a integração exige que a relação entre conhecimentos gerais e específicos seja construída continuamente ao longo da formação, sob os eixos do trabalho, da ciência, da tecnologia e da cultura." Tal visão de totalidade se expressa na práxis ensina-aprendizagem e, por isso, as práticas pedagógicas devem ser pensadas coletivamente, objetivando proporcionar ao educando conhecimentos científicos e tecnológicos do mundo do trabalho e a compreensão histórica das relações econômicas, políticas, sociais e culturais, a fim de ampliar sua leitura de mundo, o exercício consciente da cidadania e o prosseguimento de estudos.

Assim, o arranjo curricular dos cursos técnicos integrados contribui, em tese, para viabilizar a concepção de formação profissional - formação humana integral - assumida pela Instituição, pois como ressalta Tonet (2006), a formação omnilateral não se materializa na sociedade capitalista, porque exige o acesso aos bens materiais e espirituais necessários à plena realização dos indivíduos, coisas que essa sociedade desigual não permite. Isto significa que essa concepção de formação exige a superação da exploração do homem pelo homem, da sociedade dividida em classes e, portanto, só pode se realizar em uma sociedade para além do capital.

\section{CONSIDERAÇÕES FINAIS}

Na sociedade capitalista a concepção de formação do trabalhador é sempre a formação unilateral, pois privilegia apenas uma dimensão da formação humana - a laboral -, tal como imposta pela divisão social e técnica do trabalho, haja vista que o homem é considerado apenas um agente produtivo de mercadorias, que precisa ser qualificado para o saber-fazer no mercado de trabalho. Isso impõe pensar outra concepção de formação profissional distinta daquela, que tenha o ser humano e, não o mercado, como centralidade, que articule estratégias de emancipação do trabalhador, de modo que este possa tornar-se não só profissional qualificado para o mundo do trabalho, mas também cidadão consciente, capaz de compreender a sociedade para além de sua aparência, nela intervir e operar transformações. Nesse sentido, o IFRN tem muito a contribuir, na medida em que oferta cursos técnicos integrados ao ensino médio, orientados pela perspectiva da politecnia, articulando organicamente, em um mesmo currículo, trabalho, ciência, tecnologia e cultura, e tendo como horizonte a formação integral dos estudantes.

Entretanto, como demonstramos neste trabalho, nem sempre foi assim na Instituição. No período de 1970 a 1994, sob a denominação de ETFRN, e entre 1999 e 2004, como CEFET-RN, a concepção de formação que orientava as ofertas educacionais foi a formação unilateral, uma vez que o fim último dos cursos era a formação de técnicos para o setor secundário da economia, para a vida produtiva, portanto. Decerto o mercado de trabalho deve ser considerado em toda e qualquer proposta pedagógica, mas não como a referência preponderante, pois à escola cabe também proporcionar ao educando uma formação cidadã e emancipatória. Ou seja, em qualquer tempo, o estudante necessita não apenas de uma qualificação estreita sintonizada com e para o mundo produtivo, mas de uma larga formação, que lhe permita inserir-se dignamente na vida laboral, compreender como os conhecimentos científico-tecnológicos influenciam a organização do trabalho e da produção e da vida cotidiana na sociedade. 
Entre esses momentos e, depois deles, houve um processo de descontinuidade das propostas curriculares, de modo que na ETFRN, entre 1995 e 1998, no CEFET-RN, de 2005 a 2008 e no IFRN, a partir de 2009, a concepção de formação adotada foi a formação omnilateral, integral do estudante. Essa concepção foi consubstanciada na oferta, no primeiro período, das habilitações profissionais organizadas em áreas de conhecimento, que previam o interrelacionamento dos aspectos científicos e técnicos desde o início do curso; e da oferta, nos dois seguintes, dos cursos técnicos integrados ao ensino médio, perspectivados pela politecnia e pela indissociabilidade do trabalho, da ciência, da tecnologia e da cultura, como síntese da produção material da sociedade. Com efeito, havia/há nesses períodos, a intenção de se estabelecer uma educação progressista, para a transformação da realidade, e a finalidade precípua de formar o profissional-cidadão, aquele qualificado para o mundo do trabalho, para o exercício da cidadania e para continuidade dos estudos em ensino superior.

Os Projetos Político-Pedagógicos que a Instituição concebeu no período em estudo, apresentaram como especificidades a incorporação das determinações legais decorrentes da reforma do ensino de 1ㅇ e 2 o graus (Lei n. 5.692/1971) e das reformas da educação profissional (Decreto n. 2.208/1997 e Decreto n. 5.154/2004), com exceção da Proposta Curricular de 1995, que não tinha vinculação direta com aquela Lei, tornando-se um projeto inovador para a própria Instituição e para toda a Rede Federal de Educação Profissional e Tecnológica. Ademais, exibiram mais continuidades do que rupturas em relação à concepção de formação profissional adotada, ou seja, no IFRN há uma propensão, pelo menos nesses documentos institucionais, a uma formação omnilateral ou formação humana integral, consubstanciada em uma ação educativa que visa à formação mais completa do estudante, a fim de torná-lo um profissional-cidadão.

Todavia, essa concepção de formação profissional ainda não está consolidada na Instituição, e permanece como a utopia que move a ação educativa no IFRN, assim como movia a ETFRN em 1995 e o CEFET-RN em 2005, uma vez que, pelo menos nesses documentos oficiais, as atividades educativas são orientadas para uma educação progressista, para a transformação da realidade, perspectivadas pelo domínio dos fundamentos das diferentes técnicas produtivas e pela participação ativa na construção de uma sociedade justa e igualitária.

\section{AGRADECIMENTOS}

À Coordenação de Aperfeiçoamento de Pessoal de Nível Superior (CAPES), pela concessão da bolsa de estudos, conforme Proc. no BEX 5563/13-5.

Ao Instituto Federal de Educação, Ciência e Tecnologia do Rio Grande do Norte (IFRN), por viabilizar os estudos de doutorado.

\section{REFERÊNCIAS BIBLIOGRÁFICAS}

1. BRASIL. Lei n. 5.692, de 11 de agosto de 1971. Brasília, DF, 1971. Disponível em: <https://www.planalto.gov.br/ccivil_03/Leis/L5692.htm>. Acesso em: 13 jun. 2009.

2.

Decreto n. 2.208, de 17 de abril de 1997. Brasília, DF, 1997. Disponível em: <https://www.planalto.gov.br/ccivil_03/decreto/d2208.htm>. Acesso em: 20 set. 1997.

3. Decreto n. 5.154, de 23 de julho de 2004. Brasília, DF, 2004. Disponível em: 
<https://www.planalto.gov.br/ccivil_03/_Ato2004-2006/2004/Decreto/D5154.htm>. Acesso em: 22 dez. 2009.

4. Conselho Federal de Educação. Habilitações profissionais do ensino do 2ำ grau. Rio de Janeiro: Expressão e cultura; Brasília: INL, 1972.

5. CENTRO FEDERAL DE EDUCAÇÃO TECNOLÓGICA DO RIO GRANDE DO NORTE. Proposta de reestruturação curricular do CEFET-RN. Natal, RN, 1999.

6. Projeto político-pedagógico do CEFET-RN: um documento em construção. Natal, RN, 2005.

7. CURY, Carlos Roberto Jamil et. al. A profissionalização do ensino na Lei $\mathbf{n} . \mathbf{5 . 6 9 2 / 1 9 7 1 . ~}$ Brasília: INEP, 1982.

8. ESCOLA TÉCNICA FEDERAL DO RIO GRANDE DO NORTE. Organização Didática. Natal: ETFRN, 1985.

9. Proposta curricular da ETFRN. Natal: ETFRN, 1995.

10. FRIGOTTO, Gaudêncio. Educação e Trabalho: bases para debater a educação profissional emancipadora. Revista Perspectiva, Florianópolis, v. 19, n. 1, p. 71-87, jan./jun., 2001.

11. Educação e a crise do capitalismo real. 5. ed. São Paulo: Cortez, 2003.

12. GRAMSCl, Antonio. Os intelectuais e a organização da cultura. 4. ed. Rio de Janeiro: Civilização Brasileira, 1995.

13. INSTITUTO FEDERAL DE EDUCAÇÃO, CIÊNCIA E TECNOLOGIA DO RIO GRANDE DO NORTE. Projeto Político-Pedagógico do IFRN: uma construção coletiva. Natal, RN, 2012.

14. KOSIK, Karel. Dialética do concreto. 2. ed. Rio de Janeiro: Paz e Terra, 1976.

15. MACHADO, Lucília Regina de Souza. Ensino médio e técnico com currículos integrados: propostas de ação didática para uma relação não fantasiosa. In: MOLL, Jaqueline (Org.). Educação profissional e tecnológica no Brasil contemporâneo: desafios, tensões e possibilidades. Porto Alegre, RS: Artmed Editora, 2010a, p. 80-95.

16. Or. Organização da educação profissional e tecnológica por eixos tecnológicos. Linhas Críticas, Brasília, DF, v. 16, n. 30, p. 89-108, jan./jun. 2010b.

17. RAMOS, Marise. Possibilidades e desafios na organização do currículo integrado. In FRIGOTTO, Gaudêncio; CIAVATTA, Maria; RAMOS, Marise (Org.). Ensino Médio Integrado: concepção e contradições. São Paulo: Cortez, 2005, p.106-127.

18. TONET, Ivo. Educação e formação humana. Ideação, Foz do Iguaçu, v. 8 n. 9, p. 9-21 2. sem.2006. 